\title{
SUJEITO EPISTÉMICO E SUJEITO PSÍQUICO NA FILOSOFIA PLATÓNICA ${ }^{1}$
}

\author{
José Trindade Santos \\ Universidade Federal da Paraíba
}

\section{O problema}

Apesar de a leitura tradicional continuar maioritária entre os intérpretes, tem-se recentemente difundido a tendência para negar à teoria das Formas (TF) o lugar de centro de gravidade do platonismo. ${ }^{2}$ Os argumentos apresentados para justificar essa posição invocam dificuldades na interpretação das noções de eidos e idea, a par da falta de indicações sobre a natureza das Formas, a impossibilidade de atribuir teses a Platão nos diálogos, ${ }^{3}$ e sobretudo a denúncia da gravidade dos problemas postos pela teoria, no Parménides. Sem tomar posição no debate, parece-me oportuno alargá-lo, analisando a filosofia platónica - se é lícito conferir unidade à obra dialógica que a suporta, - a partir da questão do dualismo.

Para o historiador da filosofia, o tópico é importante pelo facto de impedir a assimilação da epistemologia platónica à concepção moderna de conhecimento. Enquanto esta supõe pelo menos uma relativa autonomia do

Agradeço a Marcelo Boeri a possibilidade de participar, com uma conferência na Universidad de Los Andes, em Santiago do Chile, no projecto "Apariencia y realidad en el pensamiento antiguo. Investigaciones sobre algunos aspectos epistemológicos, éticos y de teoría de la acción de algunas teorías morales de la antigüedad". Dessa oportunidade saiu a ideia para este texto, do qual foi lida uma versão resumida no XI Encontro Nacional de Filosofia da ANPOF, realizado em Salvador, em 2004.

2 Por exemplo, K. M. Sayre, "Why Plato never had a theory of Forms", in Proceedings of the Boston Area Colloquium in Ancient Philosophy 9, 1995, 167-199; mais recentemente, F. J. Gonzalez, "Perché non esiste una "teoria platonica delle idee", in Platone e ia tradizione platonica, M. Bonazzi e F. Trabattoni (a cura di), Milano, 2003, pp. $31-68$.

3 F. Trabattoni, "Il dialogo come "portavoce" dell'opinione di Platone: il caso del Parmenide", in Platone..., supra n. 2, pp. $151-178$. 
sujeito e objecto, naquela o dualismo corpo/alma - estrito nos planos ético e antropológico, - apoiado na congenitura da alma com as Formas (Ménon 81c-d; Fédon 79c-d, 80a-b), funde um no outro. ${ }^{4}$ A rigidez deste dualismo mostra-se, porém, problemática no plano epistemológico.

Ao identificar o saber (epistêmê) com as Formas, a teoria da anamnese recusa estatuto epistémico a qualquer outra forma de cognição senso-percepção, ou "opinião" (doxa), - pois não só a crença é incompatível com a posse do "saber e recta razão" pela alma (Féd. 73a), como o saber não pode ser "captado" a partir de sensíveis (Féd. 74b).

Como se explica então que as opiniões que o escravo tira de si mesmo sejam susceptíveis de se transformarem em saber $(M .85 b-c)$ ? É claro que nem a posse de opiniões, nem a elaboração a que podem ser submetidas, consentem encarar a doxa como um estado cognitivo, ao contrário do que a República (V 476d sqq) implica, ao considerá-la como dynamis.

A epistemologia platónica acha-se perante duas alternativas inaceitáveis: ou cancela a infalibilidade em que assenta o estado de saber (Gór. $454 \mathrm{~d}, R$. V 477e, Teet. 152c), rejeitando o dualismo; ou o torna inacessível, inviabilizando toda a forma de aprendizagem. O dilema não se manifesta no grupo de diálogos em que é apresentada a anamnese, associada àquilo que, por conveniência pedagógica, refiro como a "versão canónica" da teoria das Formas. ${ }^{5}$ Irrompe no Teeteto, diálogo no qual quer a ausência de Formas, justificando dúvidas sobre a vigência da teoria metafísica a elas associada, quer a contribuição da senso-percepção para a opinião e o saber, acarretam a reformulação do dualismo epistemológico.

O meu objectivo neste texto é avaliar o alcance desta reformulação, comparando a epistemologia desenvolvida no argumento da anamnese, no Fédon, com aquela que expõe, analisa e critica as teorias sobre a senso-percepção, atribuídas a Protágoras, no Teeteto.

\section{Anamnese no Fédon}

O dualismo platónico começa a ser exposto no argumento do Fédon que identifica a sensibilidade com o corpo e a alma com a Razão (65a sqq). A cisão é explorada até às últimas consequências no plano ético (66c-69e, 81b-84b), em termos que os compêndios caracterizam como caracteristica-

4 Aos loci classici do dualismo - o Fédon, os Livros centrais da República e a descrição da psico-génese, no Timeu - acrescento a sua reafirmação pontual, no Sofista 248a, a par das três versões da anamnese: Ménon 82-86, Fédon 72-76 e a imagem da alma, na palinódia do Fedro 245d-251b (vide ainda a comparação da reminiscência com a recordação, no Filebo 34a-c).

Sendo consensual a exegese destes textos, dispenso-me de os abordar extensivamente, optando por referi-los quando se levantarem questões que me pareçam oportunas.

5 Embora não a encare como o núcleo doutrinal da filosofia platónica, além dos textos já mencionados, considero este programa expresso, ou subjacente, no Crátilo e Simpósio. 
mente platónicos. Menos notada, pelo contrário, é a correspondente e capital função desempenhada pela sensibilidade na cognição. Ao longo do chamado "argumento da anamnese". vemo-la ser constantemente contraposta à Razão, numa posição subordinada, porém, sempre funcional.

\section{$2.1 \mathrm{O}$ argumento}

Depois de uma comprimida referência implícita ao Ménon (73a-b), é definido o princípio segundo o qual só pode haver reminiscência daquilo que antes se "soubera" (epistêmê, epistasthai: 73c). São depois fornecidos vários exemplos, tendentes a mostrar em que circunstâncias uma experiência cognitiva, designada "“senso-percepção", 6 suscita outra, identificada como saber (73c-74a) e caracterizada como reminiscência.

Começa então o argumento propriamente dito, concentrado nos casos da reminiscência de "semelhantes" (74a sqq: vide 73e). A comparação dos iguais visíveis com o Igual estabelece a prioridade cronológica (74e-75e), psíquica (74c-d) e epistemológica (74d-75d) da experiência inteligível sobre a sensível. Todavia, o argumento não deixa de repetidamente insistir (74c, 75a, b, e, 75e-76a) no facto de ser através da sensibilidade que "recuperamos" (analambanomen: 75e) essa experiência inteligível, designada como saber.

Apesar de os iguais não nos "aparecerem" (phainetai: 74b, d) "como" o Igual, mas por vezes iguais, por vezes desiguais ${ }^{7}$ (ao contrário do Igual, que nunca aparece - ephanê: 74b; phainetai: $74 \mathrm{c}$ - desigual), é a partir deles que "concebemos e captamos" (ennenoêkas te kai eilephas) o saber ${ }^{8}$ [do Igual] (74c). Mas o argumento não expõe claramente porquê, nem como esta concepção e captação são possibilitadas.

E não pode fazê-lo por se concentrar na caracterização da inferioridade dos visíveis (74b-e). Por isso, só adiante e pontualmente é explicada a "referência" (anoisein: 75b; anapheromen: 76d) destes à entidade inteligível que especificamente imitam (entretanto identificada como "o belo", "o bom", "o justo", "o piedoso", e "todas as outras" [...]"que são": 75c-d).

${ }^{6}$ O termo tenta reflectir a incapacidade de distinguir a sensação da percepção.

7 A leitura relativista do passo ("para mim"... "para ti") é a mais natural, introduzindo o registo doxástico da diferença. A este se acrescenta o físico, relativo à possibilidade de alteração constitutiva. No entanto, não se acha excluída a possibilidade de o ler no registo relacional, da chamada "mudança de Cambridge", pelo qual as coisas "nos aparecem" de acordo com aquilo com que as comparamos (vide Féd. 96d-e, 102b-104a; Teet. 154a-155e).

$\mathrm{O}$ interesse desta nota reside no facto de a comparação fornecer o contexto no qual se insere a "aparência": as coisas parecem-nos diferentes não apenas por se acharem sujeitas à mudança, mas porque cada um a compara com experiências diferentes.

$8 \mathrm{Em} \mathrm{74b-concedida} \mathrm{por} \mathrm{Símias} \mathrm{a} \mathrm{realidade/existência} \mathrm{do} \mathrm{Igual} \mathrm{inteligível,} \mathrm{-} \mathrm{a} \mathrm{sua} \mathrm{experiência}$ é identificada como "saber", caracterizado pela imutabilidade, nos três registos acima assinalados. 
O mistério da reminiscência (74a) - globalmente, da cognição, à qual serve de modelo -, reside nesta recíproca remissão, que enlaça o visível no inteligível. Este só é concebido (ennenoêkas) "a partir" (ek: 74c, passim; apo: 74c, 76a) daquele, pelo facto de se acharem "próximos" um do outro (hô touto eplêsiazen": 76a). Mas esta "proximidade" nunca é objecto de justificação adequada.

\subsection{Contornos epistemológicos da anamnese}

Amplificando o argumento, vemos que a única possibilidade de conferir sentido à "insanidade" sensível (vide 89e-90c) decorre do facto de a alma ter necessariamente (Fedr. 249b, e) tido contacto anterior com as Formas inteligíveis, pois as duas experiências cognitivas coexistem nela, sem nunca se confundirem uma com a outra (74d-e, 75b,76d-e, 78e-79a).

Poder-se-á, portanto, concluir que, ao contacto anterior da alma descarnada com as Formas (Mén. 81c-d; Fedr. 247d-e, 249b-d), se deve a posterior estruturação da experiência sensível: primeiro, através da linguagem (Féd. 78e-79a, 102a-b; vide $R$. X 596a; Parm. 130e), depois pelo pensamento (Teet. 184b-186c, 189e-190a), por fim pela reminiscência (Féd. $79 \mathrm{c}-\mathrm{d}),{ }^{10}$ nela residindo toda a possibilidade de atingir o saber.

\subsection{Finalidade e pressupostos do argumento}

A finalidade imediata do argumento - enquadrado no contexto do diálogo - é "demonstrar" "11 a imortalidade da alma. Todavia, o seu saldo, no plano epistemológico, é imenso, mostrando, primeiro, que, depois, como, a alma racional possibilita a captação e interpretação do real.

A tese apoia-se no pressuposto plausível de que a "deficiência" da percepção sensível não permite que a unidade e identidade da noção inteligível, fixada pela razão, expressa na linguagem ${ }^{12}$ e recuperável pela

9 Esta tradução literal parece preferível à habitual, "associados", pelo facto de esta induzir a inserção do argumento num contexto psicologístico, de todo anacrónico. Na prática, equivale a interpretar a reminiscência como um caso especial de associação.

${ }^{10}$ Esta secção do texto aproveita, com alterações, a interpretação do Fédon, proposta em "A função da alma na percepção, nos diálogos platónicos", Hypnos 13, S. Paulo 2004, 27-39. Assinalo, em particular, a associação, antes oposição (29-30), de ek toutôn (74c) a apo toutou (76a). O paralelo com apo tautês tês opseôs (74c) desfaz a ambiguidade do referente do pronome e a leitura causal da preposição, em 76a.

${ }^{11}$ Não se tratará propriamente de uma demonstração, mas antes da defesa de uma tese através da argumentação.

12 As diversas dimensões do consenso, ou acordo (homologia, symphônia, synchôrêsis), da alma consigo mesma e com outras, através do diálogo, constituem o único sintoma desta fixação. Pode ser a esta possibilidade de acordo, como condição da investigação, que Sócrates se 
reminiscência, se ache contida nela. ${ }^{13} \mathrm{O}$ argumento não consegue, porém, explicar a semelhança que associa as senso-percepções às Formas, nem porquê aquelas as "imitam" e a elas "se referem".

Finalmente, o argumento limita-se a postular a anterioridade do "saber" (73c), concedida pelo interlocutor (74b). Uma vez aceites, as diferenças (vide supra) entre as duas experiências cognitivas bastam para que Sócrates considere a de natureza mental como "saber", opondo-a à perceptiva (74b sqq). Mas é fácil entrever os problemas a que esta cisão vai dar origem.

\section{O Teeteto}

\subsection{A teoria}

Todas estas dificuldades são encaradas no Teeteto, a começar pela última. Na refutação da primeira resposta de Teeteto à pergunta de Sócrates sobre a natureza do saber - "O saber é senso-percepção" -, é desenvolvida uma complexa teoria onto-epistemológica sobre a constituição e modo de captação do sensível. ${ }^{14}$

Numa perspectiva ontológica, é-nos apresentada uma realidade reduzida à "deslocação, movimento e mistura", quantitativa e qualitativamente indiscernível, na qual "nada é de nenhum modo e tudo devém" (gignetai: 152d).

A possibilidade de captar uma realidade dominada pelo fluxo catastrófico é desenvolvida no plano epistemológico da teoria, adiante exposto. Os percebidos (aisthêta) são movimentos lentos, aos quais erradamente são atribuídos nomes que os identificam como entes (157b-c). Emitem fluxos rápidos, captados pelos percipientes (aisthanomenoi: vide 159e), eles também movimentos lentos). Aqueles penetram nestes pelos canais sensíveis (identificados pelos seus nomes: 156c), produzindo novos movimentos rápidos, designados "senso-percepções" (aisthêseis: 156d-157b).

refere, no início do argumento da anamnese, no Ménon, ao perguntar se o escravo "é Grego e fala Grego" (82b).

${ }^{13}$ Aristóteles, ignorando a oposição do sensível ao inteligível, assenta a sua epistemologia na hipótese contrária a esta, de que a mente constrói o universal a partir da experiência dos particulares (Met. A1 983, De int. 16a1, Seg. An. B19).

${ }^{14}$ A circunstância de as teorias expostas serem, no diálogo, atribuídas a Heraclito e a refinados e anónimos seguidores de Protágoras não deve impedir-nos de responsabilizar Platão pela sua autoria.

${ }^{15}$ Ao longo de 156b-e, aqueles a que chamamos "sentidos" aparecem identificados com as suas funções específicas - as "senso-percepções", - pelo termo aisthêsis. Adiante, quando a referência aos sentidos se torna inevitável, Sócrates chama-lhes organa, ou dynameis (184d 185a). 


\subsubsection{Comparação com o Fédon}

Esta doutrina começa por parecer surpreendente não só a Teeteto (155c), como a todo o leitor do diálogo, pois não se percebe que relação tem com a tese de Protágoras, inicialmente apresentada (152a). No entanto, a comparação com o passo do Fédon estudado permitirá perceber como a sua exposição contribui para a reformulação da epistemologia platónica. Começo por notar os pontos de contacto entre os dois diálogos.

Não levando em conta a diferença de contextos, é claro que os dois passos se debruçam sobre a temática da obtenção do saber (epistêmê), para um leitor actual, do conhecimento. Em comum têm ainda a atenção dedicada ao exercício da sensibilidade. Mas há profundas diferenças a separá-los.

No argumento do Fédon, a senso-percepção desempenha diversas funções. A mais saliente será a de constituir o ponto de partida da actividade cognitiva, pois sem ela, para uma alma encarnada num corpo, não poderá haver nenhuma espécie de conhecimento.

A segunda função é complementar desta, estabelecendo a senso-percepção como uma espécie da cognição, com características próprias, caracterizada pela sua inferioridade, em comparação com o inteligível. ${ }^{16} \mathrm{~A}$ terceira função constitui o cerne do argumento, pelo facto de justificar com essa inferioridade a impossibilidade de extrair o inteligível, portanto, o saber, exclusivamente a partir do sensível.

A teoria exposta no Teeteto ignora e até certo ponto nega o inteligível, na medida em que explora a identificação da senso-percepção com o saber, ${ }^{17}$ mas ela própria não tem possibilidade de se comprometer com uma tese dessa amplitude. Veja-se o argumento, a partir de 152a.

\subsubsection{Justificação da teoria}

A possibilidade de o mesmo percebido "aparecer" com qualidades opostas a diferentes percipientes conduz à identificação da "aparência" (phantasia) com a senso-percepção (152a-c). Como disse, daqui resulta a dificuldade criada pela consequente identificação da senso-percepção com o saber (152c). Como podem diferentes percipientes ter diferentes percepções do mesmo percebido, todas infalíveis?

${ }^{16} \mathrm{O}$ argumento do final do Livro V, da República, a partir de 476a, apresenta um enunciado completo destas características. Ao tentar descrever a natureza transcendente do Belo, o Simpósio $211 \mathrm{a}-\mathrm{b}$ nega sucessivamente todas as determinações sensíveis, caracterizando implicitamente a aparência (vide phantasthêsetai: $211 \mathrm{a} 5$ ).

${ }^{17}$ Mas essa identificação, que nega a identidade entre saber e Formas, característica dos diálogos sobre a TF, é da exclusiva responsabilidade de Teeteto, sendo directamente envolvida no debate da teoria só a partir da referência ao saber, na "defesa de Protágoras" (166d). 
O desenvolvimento do argumento mostra que tal estado de coisas será não apenas explicado, mas exigido, por um real dominado pelo fluxo, em que nada é, qualitativa ou quantitativamente (em termos linguísticos e anacrónicos, que nada é sujeito ou objecto de predicação).

A incompreensão da parte de Teeteto obriga Sócrates a uma longa explicação, sintetizada pela enumeração dos princípios reguladores da onto-epistemologia atrás desenvolvida, sucessivamente criticada por uma série de objecções "erísticas" de Sócrates (161c-165e), adiante superadas pela chamada "defesa de Protágoras" (165e-168c).

\subsubsection{Síntese da teoria}

Após a consideração do exemplo da percepção do "mesmo" vinho, por um Sócrates "doente" e outro "saudável”, as leis que comandam a percepção são expressas em cinco princípios:

1. (PU) Cada percepção é única e irrepetível, alterando, pontual mas definitivamente, cada percipiente, na sua relação com o percebido (159e-160a);

2. (PI) Não há percipiente sem percebido e vice-versa (160a-b);

3. (PR) O percipiente é ou devém para o percebido e este para ele; cada um deles acha-se "amarrado" ao outro, nada sendo "em si" (160b-c);

4. (PP) A percepção é privada (160c);

5. (PV) A percepção é sempre verdadeira para o percipiente, sendo cada um juiz das coisas que são e não são para ele (160c).

Todos estes princípios, em conjunto, definem as regras de funcionamento do mundo fluxista. ${ }^{18}$ É da sua introdução que decorre a epistemologia a que chamo "sensista", a qual reformula inteiramente o relativismo inicial de Protágoras. PU institui e descreve a relação percipiente/ percebido, caracterizando-a como "senso-percepção". PI define a senso-percepção como facto atómico, resultante da interacção de cada percipiente e percebido. PR estabelece a reciprocidade da acção e paixão que ligam percebido e percipiente. PP resulta das duas anteriores, constituindo o núcleo da argumentação sensista, sendo PV oferecida como conclusão do bloco. É nele que se acha substanciada a tese da verdade como correspondência da senso-percepção à relação, única e privada, do percipiente com o percebido.

${ }^{18}$ Para facilitar a exposição, cada princípio é identificado pela regra que introduz. Ao primeiro, chamaremos "princípio da unicidade" (PU); ao segundo, "princípio da inter-dependência" (PI); ao terceiro, "princípio da reciprocidade" (PR); ao quarto, "princípio da privacidade" (PP); ao quinto, "princípio da verdade" (PV). 
Da interacção de todos estes resulta implicitamente o princípio forte que caracteriza a epistemologia sensista e a distingue de todas as outras. É o "princípio sensista" (PS), de acordo com o qual nada há além da sensação, constituindo "percipiente", "percebido" e "percepção" meras referências (154a-b, 156e-157c; vide 182b).

A fundamentá-lo acha-se, no plano ontológico, o "princípio fluxista" (PF), segundo o qual a realidade se reduz ao movimento, sem que seja possível dizer "o que" se move, pois careceria de identidade (152d), restando apenas referi-lo na forma transiente com que pontualmente se oferece aos não menos transientes sentintes (152d-e, 157a-b, 182d-183b; vide 202a, 205c; vide $T i$. 48e segs.).

Implica a teoria uma relevante mudança de perspectiva na epistemologia da percepção, pela qual esta deixa de ser "explicada" pela relação entre percipiente e percebido, inevitavelmente "reais", para passar a constituir a única e autêntica realidade. Nela, percipiente e percebido não constituirão mais que meras referências passageiras, destituídas de identidade e de sentido. ${ }^{19}$ Rematando o passo, Sócrates mostra ter conseguido fazer valer o ponto de vista, de acordo com o qual há uma ligação profunda entre a resposta de Teeteto, o relativismo de Protágoras, o fluxismo de Heraclito e a resultante onto-epistemologia sensista (160d-e).

\subsubsection{Dificuldades da teoria}

São, porém, notáveis divergências entre as sucessivas reformulações da teoria, que dificultam a nossa compreensão do problema. A interpretação que Sócrates faz da tese do homo mensura é decisivamente relativista, achando-se condensada na tese: "as coisas são para cada um tais como lhe aparecem" (phainomai), repetida ao longo do argumento (152a, 158a, 166d-e, 170a; justificando a tradução "parecem", vide, a mesma cláusula com dokein: 158e, 161 c, 162c, d1, 168b, 170a, 177c3).

No entanto, a reinterpretação sensista da tese, produzida pela sua associação ao fluxismo (152d-e, .154a, 158a), nega que alguma coisa, percipiente ou percebido seja. É aqui que nasce o problema de saber como o fluxo infrene consente qualquer forma de acordo entre percipientes. Veremos que na sua formulação e na solução encontrada se expressam as duas onto-epistemologias que o Teeteto propõe: a sofística e a filosófica.

${ }^{19}$ Esta secção do texto reproduz parcialmente a análise inserida em "Filosofia e Sofística no Teeteto de Platão", Filosofia e Conhecimento, Samuel Simon (org.), Brasília 2003, pp. 55 56. 


\subsubsection{Duas soluções}

\subsubsection{1 "Protágoras"}

O problema da superação da inconsistência provocada pelo fluxo é resolvido por "Protágoras". Nenhuma contradição resulta da coexistência da verdade infalível das senso-percepções com a infinita variação de percebido e percipiente:

[...] cada um de nós é a medida do que é e do que não é, e no entanto cada um difere infinitamente do outro: para um é uma coisa e assim parece, a outro é e parece outra coisa. E estou longe de negar que exista a sabedoria e o homem sábio. Mas este mesmo a quem chamo sábio é aquele de nós que, quando as coisas são e lhe parecem mal, as muda, de modo a parecerem e serem bem. ${ }^{20}$ (166d).

E como pode consegui-lo? Mudando as "aparências" (phantasmata: 167b), ou percepções "más" em "boas", as "piores" em "melhores" (167a-c), através da persuasão ${ }^{21}(168 b)$. Protágoras "ensina" Sócrates, procedendo com ele como com outros. Leva-o a aderir à sua concepção pragmática de verdade, que sem dúvida lhe parece melhor ${ }^{22}$. A solução é simples e elegante.

\subsection{Platão}

A de Platão, pelo contrário, não é nem uma coisa, nem outra. Vamos encontrá-la no argumento que remata a refutação da resposta de Teeteto (184b-186e). Contrastando a passividade analítica do sensório com a actividade sintética da alma, Sócrates mostra que qualquer possibilidade de interpretar o sensível, quanto mais de atingir o saber, se acha fora do domínio da senso-percepção.

$\mathrm{O}$ argumento refuta Teeteto, atingindo indirectamente Protágoras, ao questionar o pressuposto da continuidade da senso-percepção com a opinião, em que se funda a epistemologia por ele proposta. Examinando os princípios da epistemologia sensista, é claro que a crítica de Sócrates não atinge os quatro primeiros (PU, PI, PR, PP), mas apenas o último deles

${ }^{20}$ Tradução de Adriana Nogueira e Marcelo Boeri, Platão, Teeteto, Prefácio de José Trindade Santos, Lisboa 2005.

${ }^{21}$ A referência é pontual, porém, incontestável: "Se te deixares persuadir por mim..." (ean oun emoi peithêi).

${ }^{22}$ Muito haverá a dizer sobre este projecto epistemológico, que a filosofia, seguindo Platão, veementemente rejeitou. Mas não é este o momento para o fazer. 
(PV), pelo facto de retirar à senso-percepção a capacidade de captar a verdade.

Numa perspectiva complementar a esta, é isto mesmo que o argumento da "auto-refutação de Protágoras" (170a-171c) prova. Ou a opinião de Protágoras é verdadeira, como a de todos os outros homens; ou difere da deles, por constituir uma teoria sobre as opiniões. No primeiro caso, é trivial, por a verdade ser independente do conteúdo da opinião; no segundo, falaciosa, pelo equívoco de não se achar incluída na classe das opiniões, ou inconsistente, por conceder a verdade aos que discordam dela.

\section{Alcance das duas propostas}

\section{1 "Protágoras"}

Interessante é a circunstância de tanto uma, quanto outra epistemologias, se apoiarem na linguagem para atingirem as suas conclusões. Para "Protágoras", é decisivo o facto do acordo. A garantia da concordância da senso-percepção com a opinião que a exprime ${ }^{23}$ estende-se à garantia da verdade dessa opinião, para quem a emite, e daí à impossibilidade da produção de opiniões falsas, seja por quem for (167a). A subsequente tese da condensação nas leis do acordo das opiniões dos homens regula o regime de relação das opiniões, no espaço da cidade ${ }^{24}$ (167c, 172a-b, 177c-d).

O sistema é empírico, mas pode ser aperfeiçoado pela intervenção de sofistas, médicos, oradores (por analogia, também de agricultores), que asseguram a substituição das senso-percepções e opiniões dos doentes por outras "melhores" (167a-c; beltiô: 167b3). Notemos que, excepto no último caso, é inegável que a acção educativa do "sábio" é levada a cabo pela palavra, ou seja, pela persuasão.

\subsection{Platão}

Quanto a Platão, o argumento corre de modo totalmente distinto. É a possibilidade de usar, na linguagem, termos que nenhuma percepção sensível pode justificar que remete para as actividades perceptual, conceptual e

${ }^{23}$ Dada pelo texto platónico. É impossível avaliar se é com correcção que Sócrates liga PV, que assegura a verdade da senso-percepção, para quem a sente $(158 \mathrm{e}, 160 \mathrm{c})$, à verdade da opinião que a exprime (vide 161e7-9), sendo evidente que Sócrates está a sobre-interpretar a tese do homo mensura. Mas esse não é o problema!

O meu objectivo é avaliar o argumento com que Sócrates refuta a tese que atribui a Protágoras, não a legitimidade da atribuição.

${ }^{24} \mathrm{O}$ único relevante, para "Protágoras". Embora o Teeteto mantenha silêncio sobre a possibilidade da relação, é perfeita a coincidência desta cidade com a Caverna platónica. De resto, abundam na digressão (172c-177c) sinais do paralelismo entre os dois passos. 
reflexiva da mente ${ }^{25}$. O primeiro uso é detectável no simples exercício da sensibilidade, o segundo na prática de comparação das percepções, o terceiro nos termos que condensam o poder de sintetizar a experiência do real: semelhante/dissemelhante, mesmo/outro, unidade/pluralidade e acima de tudo "ser" (185c-d, 186a-c). Não será excessivo agregar a estes o bem e o mal e os outros valores, a verdade e o saber (186c-d).

\section{Coerência interna da proposta platónica}

O argumento chega para afastar "Protágoras" e "Heraclito" - e com eles o relativismo e o sensismo - do mundo do saber. Mas será a proposta de Platão consistente? Em que pressupostos se funda o recurso à análise da linguagem para definir uma epistemologia?

Claramente no de que nomes e verbos constituem expressão da actividade superior da mente; da racionalidade, diríamos hoje. No Fédon, este pressuposto acha-se associado à hipótese da realidade das Formas e ao argumento da anamnese. No Teeteto, nenhuma destas concepções é explicitamente afirmada, embora não se achem excluídas.

A ligação directa da linguagem à Razão suporta mal a contaminação pelo exercício da sensibilidade. A tese de que o sensível imita o inteligível - exposta no Fédon, República e Timeu, implícita em muitos dos passos em que o dualismo platónico noutras obras se manifesta - resolve a dificuldade. Mas, se o Teeteto não faz qualquer referência à imitação, como poderá explicar essa "semelhança", estruturante de toda a experiência sensível, resultante da associação desta a um prévio contacto com o seu "referente" inteligível?

É aqui que a contribuição do Teeteto para a tradição filosófica se mostra fecunda. No lugar da imitação, Platão serve-se de dois verbos para indicar como as senso-percepções se formam nos percipientes e são por eles expressas: dokein e phainomai.

Ambos desempenham uma função capital, no diálogo e na versão crítica da epistemologia platónica. Dokein e doxa dominam a segunda parte da obra, caracterizando a actividade reflexiva da mente e abrindo a única via conducente ao saber ${ }^{26}$. Phainomai dá origem a uma família de termos (phainomenon, phantasia, phantasma), usada na primeira parte, para carac-

${ }^{25}$ Pelas quais a alma recebe uma percepção (184e-185a), a compara com outras (185a-b), podendo reflectir em conjunto sobre a totalidade da sua experiência, visando o saber (185c-186d). Esta actividade conceptual e perceptiva da mente esclarece o modo como a anamnese "estrutura" a experiência sensível, integrando-a na anterior experiência epistémica da alma.

${ }^{26} \mathrm{Na}$ realidade, do meu ponto de vista, contribuindo para o abandono da concepção eleática de saber, da qual decorre a estrita dualidade dos estados opostos do saber e da ignorância, caracterizada pela irrefutabilidade. 
terizar as versões relativista e sensista de Protágoras, na tese de que "as coisas são para cada um como lhe aparecem".

Ao todo, conta-se mais de uma vintena de aparições qualificadas destes termos, concentradas em três blocos:

$152 a-154 a(7: 152 \mathrm{a} 7, \mathrm{~b} 9,11, \mathrm{~d} 5,153 \mathrm{e} 7,154 \mathrm{a} 3,6)$;

$157 d-158 a(5: 157 \mathrm{~d} 10,158 \mathrm{a} 2,3,6,7)$;

$166 c-e(5: \mathrm{c} 6, \mathrm{~d} 4,7, \mathrm{e} 3,4)$;

mais 4 isoladas $(159 \mathrm{c} 11, \mathrm{~d} 5,161 \mathrm{e} 8,167 \mathrm{~b} 3) .^{27}$

Haverá algum sentido em isolar esta leitura técnica de phainomai e correlatos, essencial para compreender a articulação do Teeteto com o Fédon? O passo 264a, do Sofista confirma esta possibilidade, apresentando, inserida na investigação sobre a natureza do sofista $(240 \mathrm{e}){ }^{28}$ a definição de phantasia, entendida como a manifestação da opinião na mente "através da senso-percepção".

\section{Consequências da inovação}

Onde nos leva esta conclusão? A supor que, afastada a tese da verdade necessária das opiniões, Platão pode fazer concessões ao relativismo de Protágoras, sobre a refutação do qual exprimirá reservas $(179 \mathrm{c})$. É que, apesar de o argumento final da primeira resposta eliminar o pressuposto da continuidade entre a senso-percepção e a opinião, o poder da aparência é bastante para exigir, em contraponto com o sujeito epistémico, a criação de um sujeito psíquico, coordenador das actividades perceptual, conceptual e reflexiva da mente. Que quer isto dizer?

\subsection{O problema revisitado}

Comecei, apresentando uma tese, que a seguir justifiquei. Os paradigmas das epistemologias platónica e moderna são incomensuráveis, pois, enquanto Platão busca o saber, que identifica com as Formas, pelo menos a partir de Descartes, o problema da epistemologia é o do conhecimento (do real). A incomensurabilidade justifica-se pela associação do projecto anamnésico à $\mathrm{TF}$, que concede à senso-percepção uma função meramente instrumental.

${ }^{27}$ Repita-se que Platão não se coíbe de recorrer a dokein para se referir à tese relativista (158e6, $161 \mathrm{c} 2,162 \mathrm{c} 8, \mathrm{~d} 1,168 \mathrm{~b} 5,170 \mathrm{a} 3,177 \mathrm{c} 3)$.

${ }^{28}$ Já antes, na avaliação da natureza da relação entre a mente e o ser, fora afirmado o paralelismo da participação do corpo na geração, através da senso-percepção, com a da alma/mente no ser, através do pensamento (248a). Esta posição é coerente com idêntica distinção, estabelecida no Timeu (27d-28a, 51e). 
Esta associação, porém, traz consigo um novo problema. Estará a epistemologia platónica condenada a circular eternamente na TF? A interpretação do Teeteto serviu para apresentar respostas diferentes a esta pergunta. Para F. M. Cornford, ${ }^{29}$ o Teeteto constitui uma reductio de qualquer tentativa de alcançar o conhecimento (knowledge), que dispense a TF. Para G. Ryle, pelo contrário, representa o abandono do projecto da TF por Platão. ${ }^{30}$

A interpretação aqui apresentada não aceita nenhuma destas, defendendo que nem o Teeteto constitui uma reductio, nem o abandono da TF. O argumento do diálogo mostra apenas que a concepção eleática de saber, na qual se apoia a versão canónica da TF, só produz aporias, quando a cognição abarca o exercício da sensibilidade numa série de operações mentais, distintas e integradas na actividade da mente.

O Sofista complementa o projecto, propondo uma versão da TF, da qual se acha ausente a tese eleática de que ser e não ser são idênticos a si próprios e contrários um ao outro. Constitui novidade desta proposta o recurso à TF para estudar a aparência sensível.

Significa esta afirmação que a TF passou a visar o conhecimento, deixando de se achar limitada à tentativa de atingir o saber das Formas imutáveis? É para esta possibilidade que a análise de phainomai remete. A intervenção da aparência acaba com a especificidade das competências cognitivas (Rep. V 477a-478d), caracterizadas por designações, conteúdos e

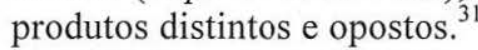

No Teeteto, a doxa não remete exclusivamente para a doxa, tal como a epistêmê para o ser, sendo suspenso o princípio da congenitura da alma com a Formas (Mén. 81e-d). Pelo contrário, a finalidade do diálogo é explorar a única possibilidade com que a investigação se confronta: a do recurso à doxa constituir a única via para atingir o saber.

Paralelamente, o exercício da sensibilidade deixou de constituir um impedimento para o acesso ao inteligível, uma vez que se presta a ser trabalhado pela alma. Por fim, o erro, de que a razão se achava livre, tornou-

${ }^{29}$ Plato's Theory of Knowledge, London $1935^{1}$; vide a tentative de reabilitar Cornford, criticando M. Burnyeat, em G. Adalier, "The Case of Theatetus", Phronesis XLVI, Leiden 2001, pp. $1-37$.

${ }^{30}$ Os principais simpatizantes da tese de Ryle (expressa em "Plato's Parmenides" Mind 48, 1939, pp. 129 - 151; e "Logical Atomism in Plato's Theaetetus", Phronesis 35, 1990, pp. 2 16) concordam na rejeição da interpretação de Cornford, mas não se comprometem com a tese do abandono; vide R. Robinson, "Forms and error in Plato's Theaetetus", Philosophical Review 59, 1950, pp. 3 - 30; John M. Cooper, "Plato on Sense-Perception and Knowledge (Theaetetus 184-186)", Phronesis 15, 1970, Assen, pp. 123 -146; M. F. Burnyeat, The Theaetetus of Plato (translation by M. J. Levett), Indianapolis/Cambridge 1990.

${ }^{31}$ Desinteressando-se das consequências éticas, morais e religiosas da subversão da alma pelo .corpo (Féd. 65d sqq), bem como do estudo dos conflitos entre as "partes da alma" (República IV). 
-se possível quer pela intromissão da sensibilidade e da memória, quer pelo exercício da actividade que lhe é própria (vide o símile do aviário).

\section{Sujeito epistémico e sujeito psíquico}

Sustentei acima a incompatibilidade da versão canónica da TF com as noções de sujeito e objecto do conhecimento. Há, contudo, nos diálogos dois sinais da emergência de um sujeito e de um objecto específicos do saber. Na República VI 508e-509b e no Crátilo 440b, Sócrates refere-se a "cognoscentes" e "cognoscíves", a "visíveis", ${ }^{32}$ num contexto em que as Formas se acham bem presentes, na posição de objecto. Manifesta-se aqui um sujeito epistémico a comandar a cognição. Todavia, como ambos os contextos deixam bem claro que essa função é atribuída à alma, trata-se de um sujeito transcendentalmente entendido, ao qual cabe a função arquetípica de contactar com o inteligível.

Pelo contrário, a manifestação da phantasia, que, no Teeteto, tem o sentido de "aparência", e, no Sofista, acumula com este o sentido operacional, de "imaginação", apresenta um cunho marcadamente subjectivo, designando estados de alma como desejos, temores, dores, emoções, além de uma infinidade de outros, inominados (Teet. 156b; Féd. 69a-b), coexistindo no percipiente com as senso-percepções propriamente ditas, atribuídas ou não a um órgão específico (Teet. 156b).

Mais adiante, Sócrates acrescentará que este percipiente não só sente, como pensa, pergunta e responde, define, recorda-se e esquece, calcula, acerta e erra, nas suas muitas tentativas para chegar ao saber. Portanto, o diálogo já não deixa o leitor perante uma hipóstase, designada para representar uma função cognitiva, mas um indivíduo concreto, protagonista de um experimento em cognição: sejam Sócrates, Teeteto, ou Teodoro.

Este sujeito do conhecimento confronta-se com objectos interiores e exteriores a ele, recorrendo não apenas ao corpo, mas sobretudo àquela figura da alma, a que a modernidade se virá a referir, com designações como "espírito", "mente", "entendimento" ou "razão", consoante o perfil ideológico que tiver adoptado.

A ser assim, haverá boas razões para pensar que a epistemologia platónica dispensou a anamnese? Não forçosamente, embora não seja possível considerar aqui os argumentos positivos para defender a sua presença na obra platónica. Noto apenas que, confrontada com o fluxo, esta nova função da psychê dissipou o mistério da "semelhança", estabelecendo a continuidade do sensível com o inteligível.

${ }^{32}$ Respectivamente, nos dativos plural passivo (Rep. VI 508e1-2, 509b6) e singular activo (e2) do particípio, e no nominativo e acusativo neutros do particípio, activo e passivo (Crá. 440b5). 
S. - Espera aí: ela [a alma] não aperceberá a dureza do que é duro através do tacto e, da mesma maneira, a moleza do que é mole?

TEET. - Sim.

S. - Então a própria alma, recapitulando e comparando umas com as outras [sc. a dureza e a moleza], tenta esclarecer-nos, acerca da entidade, que ambas são, que estão em oposição uma à outra e ainda sobre a realidade da oposição.

TEET. - Certamente.

S. - Portanto, há coisas de que tanto homens, como animais, mal nascem, por natureza se apercebem, como aquelas paixões do corpo que se dirigem à alma; mas o resultados dos cálculos, no que respeita à entidade e à utilidade, é dificilmente e com tempo que chegam àqueles a que chegam, através de muito trabalho e pela educação. (Teet. 186b-c).

Trata-se então de uma invenção do conhecimento, renovadora da concepção platónica de educação? Olhando para trás, para Parménides, sem dúvida. Mas o estudo da tradição posterior revelará o muito que ainda há para descobrir e pôr em prática, para que se tenha chegado à relação dual de que falei no início. Mesmo assim, poderá dizer-se que, num único diálogo, a epistemologia se assumiu como disciplina autónoma, abrindo caminho a problemas que a actualidade ainda não conseguiu resolver.

\section{Abstract}

This text aims to show how the inclusion of sense-perceptions in cognition reformulates Plato's "canonical version of the theory of Forms" (TF). Knowledge is no longer understood as the activity of a formal, epistemic, subject, but of a psychological one.

In those dialogues dedicated to the exposition of the TF Plato's view of cognition is based on the identification of epistêmê with Forms (according to the model of anamnesis). In the Theaetetus, however, sense-perceptions are related to knowledge in a way which sees the psychê no longer as an impersonal soul, travelling through a succession of bodies. Plato's analysis of doxa takes psychê as a feeling and thinking, irreducibly personal, subjective mind. 
